Case Reports

\title{
Anamorphic Cartograms and Environmental Risk Analysis
}

\author{
${ }^{1}$ Chiara Porporato, ${ }^{1}$ Tamara Bellone and ${ }^{2}$ Francesco Fiermonte

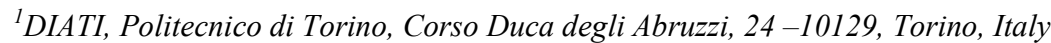 \\ ${ }^{2}$ DIST, Politecnico di Torino, Viale Pier Andrea Mattioli, 39-10125, Torino, Italy
}

\author{
Article history \\ Received: 18-8-2016 \\ Revised: 19-11-2016 \\ Accepted: 22-11-2016 \\ Corresponding Author: \\ Chiara Porporato \\ DIATI, Politecnico di Torino, \\ Corso Duca degli Abruzzi, 24 - \\ 10129, Torino, Italy \\ Email: chiara.porporato@gmail.com
}

\begin{abstract}
Both Geography and Statistics use graphical representations. Information Technology has enhanced the visualization of data, beyond the traditional aspects, to such an extent that we can nowadays speak of an "image society". Traditional thematic mapping also shows transformations of a variable over time, linking the geographical datum to the time variable. For some decades now a number of cartograms have been in use, for which the base area is displaced as a function of a particular factor, these are known as anamorphic cartograms. An anamorphic map is easier to read and may give an overview of a geographic whole.
\end{abstract}

Keywords: Anamorphic Map, Cartograms, Risk Analysis

\section{Introduction}

After some considerations on anamorphosis and its applications in history, the authors discuss briefly of the type of representation used by geographers and statisticians.

Then follows a concise presentation of the physical theory on which is based the realization of anamorphic chart.

Given the flexibility of anamorphic charts, the authors have studied the use of these cards in the environmental field.

In particular, by using the data of Italian environmental risk, were realized some cartograms that summarize graphicallythe information on risk level (i.e., landslide, hydro-geological, seismic and fire risks). These maps are a simple support, easy to read that does not require specific knowledge because it is of immediate interpretation. The authors want to analyze if this cartographic product can overcome the general inadequacy of communication between specialists and civil society in order to make these maps a good ally in the various stages of the study of the problems of environmental risk.

\section{Prologue}

The following text is a brief history of anamorphosis, a word first used in the 17th century, although the process itself had been experimented with long before.

In fact, perspective, discovered in the 15 th century, offers the third dimension and, while it is often taken to represent a type of realism, it remains an artifice and, as such, it lends itself to different uses, including the creation of optical illusions or even deformations of ordinary reality. Indeed, the distinction between art-copy and art-evocation goes back to Plato, with reflections on the difference between object and vision fascinating scholars, philosophers and artists throughout history.

Lorenzo Ghiberti, Tommaso di ser Giovanni di Mone Cassai, known as Masaccio, Leon Battista Alberti, Piero della Francesca, Leonardo da Vinci, Albrecht Dürer, Jacopo Barozzi da Vignola are the best exponents of compositions and artifices based on Optics and Geometry.

In the history of art, of the variety of ways of representing three dimensionality on a flat surface, perspective is often taken to be that closest to reality, though also as being a symbolic technique like any other. Ernst Gombrich and Erwin Panofsky, respectively, are major proponents of these two opposing views: The former (Gombrich, 1965) bases his ideas on the psychology of perception (Gestalt), developed from Husserl and from Kant's theory of knowledge: Kant states that Euclidean space is a priori human knowledge (obviously, he knows nothing of new aspects of nonEuclidean geometries, discovered long after his lifetime).

Panofsky, in contrast, works from theories about human vision (Panofky, 1984): Indeed, as Kepler already knew in his day, some straight lines may be perceived as curves, due to the curvature of our retinae (Odifreddi, 2011). In this case, a priori Euclidean space is left behind: If any space is an a priori concept for the perception of the world then this may be an elliptic space (specifically a spherical one), or a hyperbolic one.

Panofsky may be right in this (taking the classical perspective to be a symbolic process): It is useful to remember what contemporaries thought of the early 
works of Van Gogh, Degas or Cézanne, as these masters depict what they really see, far removed from what they would paint following the classical rules of perspective. Consequently, a certain degree of rejection on the part of the general public was to be expected at the time, because the rules of perspective had already penetrated the public unconscious (Odifreddi, 2011).

According to (Kemp, 1999) both views are valuable: Different types of perspective do exist: An image on the retina is indeed a central one, but only at horizontal middle distances; images are, in contrast, deformed for objects which are either very close or very distant.

Artists in antiquity, indeed, used deformations for specific purposes: A statue by Fidias, which would appear unnatural at ground level, could be appreciated in all its splendour when placed at the exact height envisaged by the sculptor (even if this caused Plato to object since the "corrections" distanced the work from reality).

Early interest in anamorphosis is associated with Leonardo's experience of examining issues posed by distortion at the periphery of vision concerning the necessity to paint curved surfaces when the viewpoint is oblique (Gian Paolo Lomazzo describes these as problems of "inverse perspective").

Anamorphic applications become more frequent towards the end of the 16th century and while the first anamorphic pictures come from North Europe, theoretical studies are largely developed in Italy, by Leonardo and others.

'Costruzione legittima' is one of two applications of perspective, since the system can work in both ways. Indeed, a square in perspective becomes a trapezoid, but there is nothing to stop a trapezoid appearing to be a square, by an inversion of the viewpoint (which is shifted to a position above the principal point, at an appropriate height, equal to the distance between the distance point and the principal point).

Once the principles have been calculated, a number of developments may follow, including specular, conical or cylindrical anamorphosis. At any event, here we are dealing with images that, when viewed head on, are hard to understand and sometimes disturbing but which appear understandable and even harmonious when looked at from a specific angle.

Later, in the seventeenth century, Jean François Niceron, Marin Mersenne and Emanuel Maignan, three scholars, monks of the Order of Minims, expert in optics and geometry and in contact with Descartes, assert that what appears, at first, strange and fanciful is not due to chance nor to supernatural phenomena and that, furthermore, techniques used to record and describe and imitate the real world do not serve merely to represent reality, but also to reveal it.

According to Descartes, optical illusions can be constructed, as well as deconstructed and unmasked, by the laws of vision: Indeed, the subject of illusion is at the heart of his thought.
For Niceron, anamorphosis is not merely a trick of the light, but rather a way to detect the presence of something hidden or unclear. La perspective curieuse (1638) and Thaumaturgus opticus (1646) are the masterpieces of this enfant prodige who, at the age of 18 , is already writing about Optics and who dies at only 33 years of age.

The first of these works begins with a description of the principles of perspective, starting with the first five regular solids, before proceeding to discuss more complex composite, irregular or hollow solids.

Even more interesting is the part outlining the rules for producing images, which at first sight appear deformed, but which acquire harmonic proportions when seen from a particular viewpoint (the first example is a chair). Lastly, catoptric anamorphosis is described (images viewed in a mirror), together with elements of Dioptrics.

Figures of Saints on the walls of the Minim monastery in Paris, at times hard to perceive, viewed from a different angle, suddenly reveal their magnificence and remind us of worldly vanity (Baltrušaitis, 1978).

Matters regarding the illusion of the senses captivated Descartes just as they had Plato. In his "Discourse on the Method", the former says "I have ever remained firm in my original resolution... to accept as true nothing that did not appear to me more clear and certain than the demonstrations of the Geometers had formerly appeared".

At a certain point in his essay "La Dioptrique", Descartes observes that, when one holds a small ball between crossed fingers, our senses deceive us, making us believe there are two balls; he also finds other cases of the senses being tricked (distorted images, too, deceive when not viewed from the correct angle).

Both painters and philosophers are wont to reflect upon illusion and truth and consequently we have many (totally or partially) anamorphic pictures.

As an example, we present below a portrait of Edward VI of England (Fig. 1), clearly distorted by anamorphosis, to be compared with the normal proportions, when seen from the right viewpoint.

"The Ambassadors" (Fig. 2), a famous painting by Holbein, shows two French ambassadors, standing and looking to the front, leaning against the upper of two shelves, on which a celestial globe, some astronomical instruments, a book and a sundial are to be seen, while on the lower shelf there is a terrestrial globe, a square and compass, two books and a lute.

These objects symbolize the liberal arts, from astronomy to geometry, from mathematics to music, but, at the same time, evoke the art of perspective, since they feature regularly in treatises on perspective. 

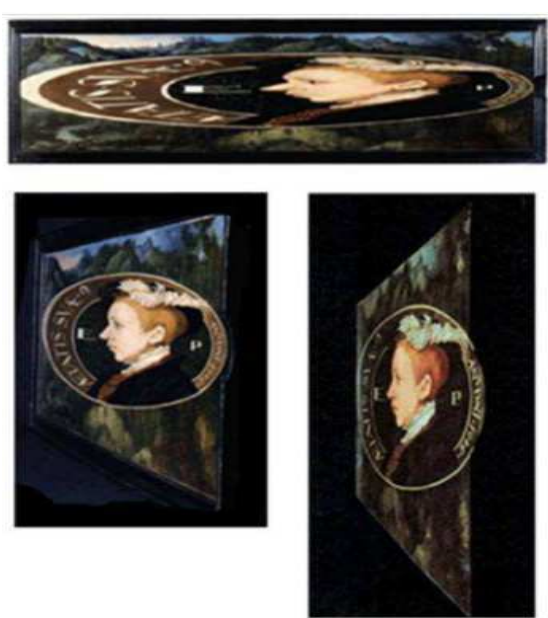

Fig. 1. Williams Scrots (1546): Anamorphic portrait of Edward VI, London National Gallery

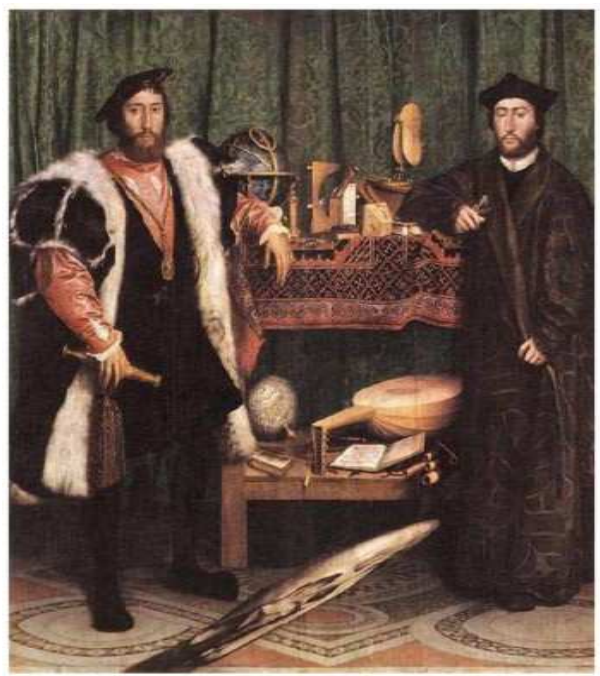

Fig. 2. Hans Holbein (1533): The Ambassadors, London National Gallery

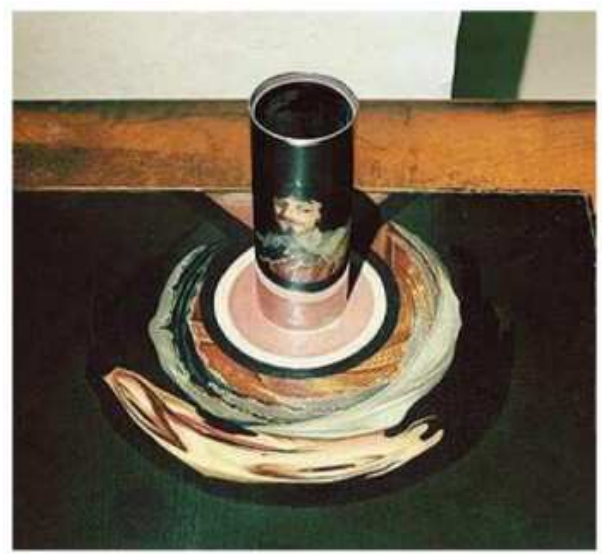

Fig. 3. Jean François Niceron (1635): Anamorphic portrait of di Louis XIII, 1635, Rome, Palazzo Barberini
At bottom right, a strange object lies on the floor: It is a skull, recognisable as such, however, from a single viewpoint alone. The anamorphic image of the skull (which completes the evocation of perspective already seen in the aforementioned objects) represents the vanity of the arts, of the sciences, of power and is in keeping with the Nordic tradition of the "Triumph of Death".

However, anamorphosis can also be used for playful ends (mainly, the spherical and cylindrical ones), such as for Chinese illusionist tricks (Fig. 3).

\section{Data Visualization}

Both Geography and Statistics use graphical representations. Information Technology has enhanced the visualization of data, beyond the traditional aspects, to such an extent that we can nowadays speak of an "image society".

Edward Tufte, statistician (and sculptor), is considered one of the experts of Infographics: He thinks it is necessary remove from the picture all the elements that are not essential to the understanding of the message (Tufte, 1983).

Charles Minard was a pioneer in the use of graphics: His is the famous representation of Napoleon's disastrous Russian campaign and specifically, the thematic map of human losses: Carte figurative des pertes successives en hommes de l'Armée Française dans la campagne de Russie 1812-1813 is cited as being one of his most successful maps (Fig. 4).

The importance of visualization of statistical data has been recognized since Tukey's day, although other statisticians had invented and made use of graphical representations (Tukey, 1977).

According to Tukey, graphical methods are mainly used for the qualitative description of the data (tables and numerical series are more useful for accurate quantitative representation) and for comparisons.

However, they can arouse greater interest than series of numbers... Data may be represented according to whether they relate to a single phenomenon or several (univariate or multivariate statistical analysis), they are distributed over a single line, or have different directions, they are numerical or categorical data.

As regards univariate statistical analysis, the following data representations are well known: Histograms, box-plots, box-and-whisker plots, steamandleaf diagrams, scatter plots, etc.

For multivariate statistics, on the other hand, we should remember: Convex hulls, scatter matrixes, Chernoff faces (Fig. 5) and so on.

Other tools are known in Geostatistics (semivariograms) and in Directional Statistics (circular histograms,..) (Fig. 6). 


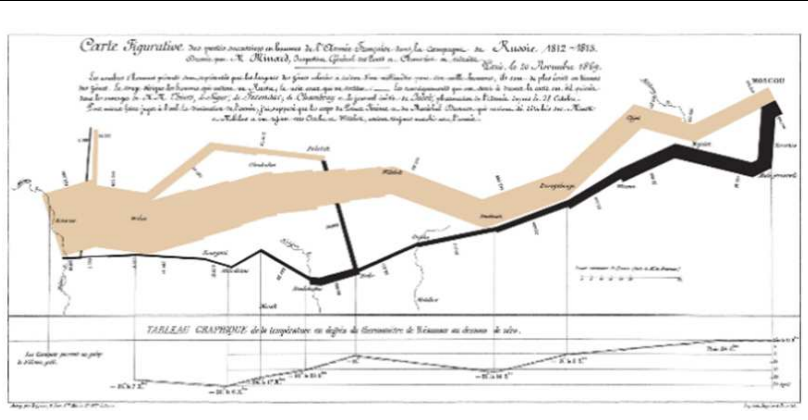

Fig. 4. Charles Minard: Chart of human losses in Russian campaign (1812-1813)

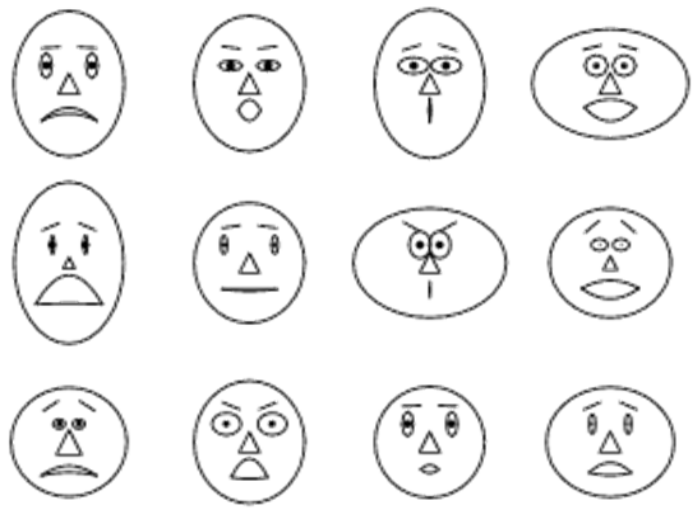

Fig. 5. Chernoff faces

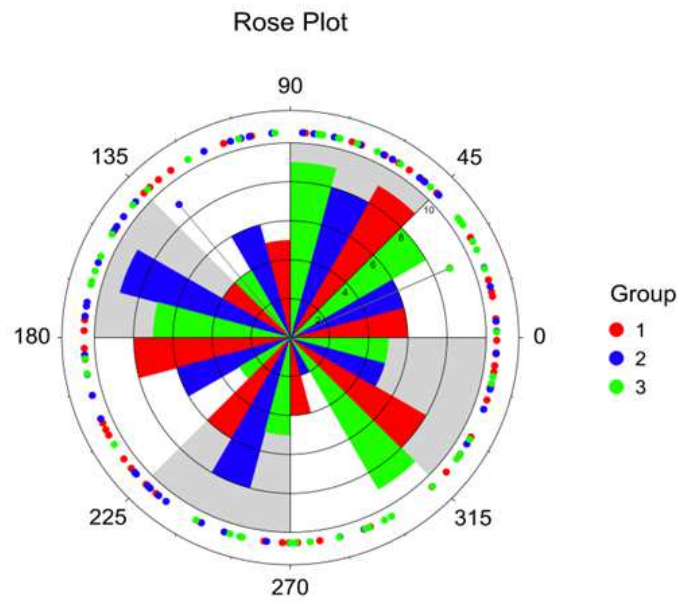

Fig. 6. Circular histogram

Thematic Cartography, unlike classical maps showing only natural features, stresses spatial distribution of a particular variable: Temperature, agricultural features, population density and so on. It also makes it possible to explain transformations of a timevariable datum, such as a migration or spread of a plague. A thematic map links geographical data to proper time variables. Moreover, it clearly shows intercourse of significant features, so facilitating analysis of geographical correlations.

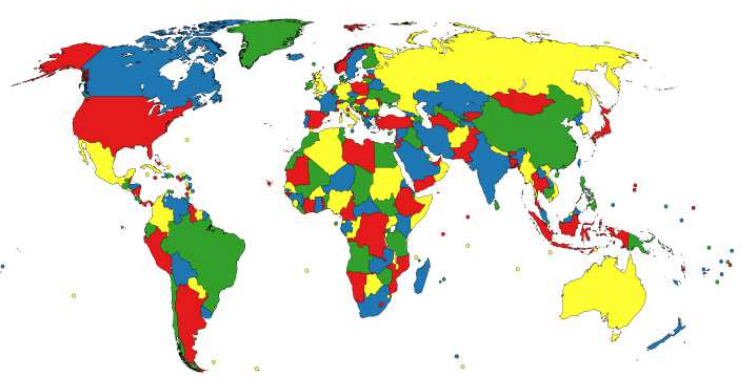

Fig. 7. A representation using four colors

Elisée Reclus, Charles Perron and Prince Kropotkin were eminent scholars in this field (Fig. 8).

Réclus, is the author of a magnificent "Nouvelle Géographie Universelle" (19 volumes), which was published in a number of monthly issues intended to be read by a wide audience. "Comparative geography", based on the Globe and no longer on a plane representation of the Earth owed its appearance some decades earlier to Von Humboldt and Réclus develops his view of a dynamic relation between Nature and Man, of the Mediterranean Sea as an integrated area of exchange, of a river as a unique environment, of "climatic belts" as a basis for the great East-West migrations (Reclus, 1876-94). Réclus and Kropotkin are joined in their continuous endeavors to teach the young the correct vision of the Earth as a solid, with a correct reproduction of relief on its surface (Ferretti, 2007).

In order to draw a thematic map, once the physical area under examination has been chosen and an appropriate projection selected, the key questions which arise concern the choice of a set of statistical issues to be investigated and of a correct method for the representation of variables. For an efficient representation, color is a key element. The four-color theorem states that four colors alone are sufficient to depict adjacent areas although maps displaying only four colors are quite uncommon (Fig. 7).

It may be necessary to take into account relations between topics on maps: So, the metric concept gives way to a topological one, following Euler's invention of graphs.

In the following, most used thematic maps are recorded.

Dot maps (or maps with density of points), use the dot symbol to stress presence of a theme in a spatial model. One-to-one dot maps, as well as one-to-many dot maps are both used widely, the second occurring more frequently. On a cartographic base, data are reported as aggregate variables.

Maps with proportional symbols are much used for the recording of statistical variables, due to the number of associate variables for every point of any position. Proportional symbols may record more than one variable: Due to the vast range of usable symbols, this method proves very flexible. 


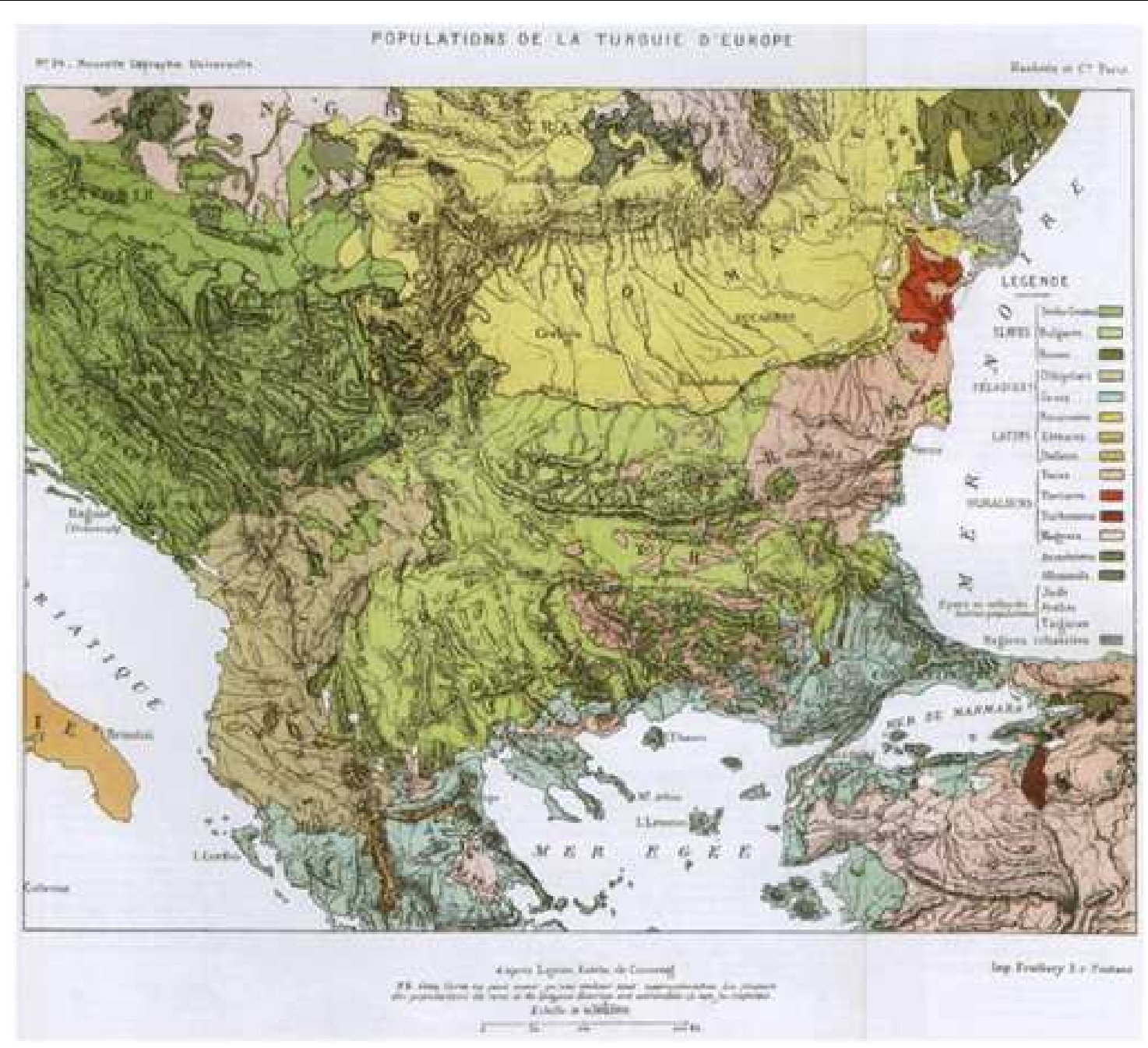

Fig. 8. Thematic chart of languages in the Ottoman Empire

Choropleth maps have shaded or colored areas, proportionally to the value of interest.

Isopleth maps have lines on the map, linking the same value of a given topic and are best suited for visualization of uniform variations in space, but should not be used for discontinuities or sharp local variations. Flux maps are a merger of maps and flow diagrams. They are designed to show movements from one place to another at a certain time.

A large range of statistical methods seek possible models for data, in order to have a better comprehension of spatial data. Of course, interaction between charts and statistical texts (graphs and tables) is of great use in investigating complex phenomena.

Since the nineties, GIS has become more and more popular thanks to its ability to cope with a huge mass of data. With GIS, a wide number of data sets may be stored in memory and classified in layers, which may be called up and displayed at any moment. GIS's potential for visual analysis is of interest when testing diverse arrays of information in order to identify the underlying data.

\section{The Theory of Diffusion: The base of the Cartogram and the Equalization of Density}

The purpose of traditional thematic mapping is to show the time transformations of a given variable by combining the geographical data with the time variable of the variation. It also displays the relationship between the most important attributes and facilitates the analysis of geographical correlation. In the implementation of thematic maps, once the physical area of interest has been chosen and a suitable map projection has been selected, the analysis of statistic sets and the choice of methodology to represent the variables are fundamental issues; often the color is a key attribute to create an effective thematic map. 
For some decades we have seen the use of cartogram in which the area of thematic analysis is deformed on the basis of the characteristics examined (Anamorphic Cartograms). An anamorphic map is easier to read.

The first creator of modern automatically generated cartograms, Tobler (1961), also wrote a history of the algorithms used for making them (Tobler, 2004).

Many researchers have built cartograms in which the size of the regions was proportionate to their population or to some other property (or statistic variables). Unfortunately, sometimes, in this type of representation the regions analyzed are not easily recognizable because the constraints to assemble the various regions produce distortions that make the paper difficult to read. The construction of these maps makes the performance of calculations time consuming. There is an algorithm developed by (Gastner and Newman, 2004) Department of Physics and Center for the Study of Complex Systems at the University of Michigan, Ann Arbor, based on the theory of diffusion that allows one to create "diffusion-based" cartograms which are easy to read.

In a distribution cartogram, the distribution must be uniform and, once the areas have been resized to be proportional to the variable, by definition, the density has the same value everywhere. Given a particular distribution, it is possible to define a cartogram allowing elements to "flow" from areas with higher density to areas with a lower density until the density becomes uniform, as in a process of diffusion described in Elementary Physics. Without studying the implementation of the algorithm, below we analyze the principles of the method and numerical solution of the algorithm. The variables used are represented by a density function of the geographical location and time. At the time zero the value of the density is that observed; subsequently it allows the density to spread. The density at a given time, by measuring the size and the direction of flow, is given by multiplying the speed for the density in a given position at that time. In the theory of linear diffusion, the current density follows the gradient of the density field. The flow, therefore, is always directed from the regions of high density to the regions with low density and it is much faster if the gradient is steeper. Conventionally, there is a constant of diffusion which defines the time scale of the diffusion process. However, as long as the study concerns only a infinite time, it is possible to impose the constant of diffusion equal to one, without loss of generality.

The elements in diffusion are kept locally and by combining the relations established previously, the equation of diffusion obtained in terms of density. Moreover, this also gives the expression of the velocity field. The cartogram processing is given by solving the equation of diffusion as a function of density, starting from the initial condition in which the density is equal to the given density of the region of interest and then calculating the relative velocity field. The cumulative displacement of any point on the map at a given time and limit values for each point of the original map, define, then, the cartogram required.

Since the analysis is typically limited to particular areas of the globe and not to its entirety, a condition of neutral threshold is applied, making the area of interest "float" in a "sea" of uniform density equal to the average density of the whole area of interest, this by dint of the fact that the areas of interest have borders or coast lines beyond which the density is not known or is not relevant.

In practice, the entire system can be thought of as being enclosed in a "box" with defined dimensions bigger than the area of interest. The boundary condition is the Neumann condition which requires the absence of flow through the edges of the "box".

The implementation of the algorithm requires calculation operations to be carried out in a short time. For this reason, the equation of the diffusion is solved in the Fourier space in which the equation assumes diagonal form, anti-transforming before integrating the velocity field. With the Neumann condition, the cosine basis of Fourier is appropriate, where the sums are above all wave arrays and the operation requested is a discrete cosine transform.

These operations can be performed quickly, using the Fast Fourier Transform, with computational complexity proportional to the product of the size by the sum of their logarithms. Then, the values of the velocity field are used in the integration of the differential equation that describes the cartogram suitably deformed that is a nonlinear Volterra equation, numerically resolvable with the standard method.

Subsequently, before applying any algorithm, it is necessary to determine the density function of the map. Therefore, to build a cartogram, it is necessary to define the distribution function; for this step there is no standard approach. Much of the success of the cartogram realization lies in finding the most suitable method to characterize the density, according to the specific case. By appropriately defining the density function of the map it is possible to control the properties of the resulting map and, above all, the balance between the accuracy of the equalization of the density and readability of the representation.

One advantage of the Gastner-Newman algorithm is independence from the choice of the density function (assigned to the user); in this way, the process of calculating the cartogram is totally decoupled from the definition and from the compromises relating to the chosen function of density. An important measure is the relative error that is the accuracy of the algorithm that defines what final areas are proportional to the population or to another density function (however chosen), in function of the area of a single region on the cartogram, of the total area of the regions, of the population of a single region and of the total population of the regions. 
The approach above summarized is certainly a tool of considerable interest for the representation and analysis of geographic data.

\section{Charts and Environment}

An anamorphic chart is easy to read, giving an overall view of a question of environmental management, whether local or national.

Recently, Italian Civil Defense has disseminated the results of its studies and plans widely, especially for teaching purposes. Obviously, everybody should know the plans in case of emergency and how to respond correctly in the circumstances.

Unfortunately, this is at present almost utopian in the everyday reality of this Country, as people lack the basic information about the real state of the environment.

Italians are rarely conscious of the high degree of seismicity, hydro-geological risk or landslide occurrence present in their country. This is also due to general inadequacy of communication between specialists and civil society. Thus, a proper chart is a very important vehicle for the diffusion of information, as long as it is easy to understand. Here follow some examples concerning environmental risk.

\section{A Visual Representation of National Hydro-} Geological Risk

Hydro-geological risk ensues from high rainfall, overflow of minor watercourses on the ground. In Italy a complex topography and generally small drainage basins (and consequent short response times) represent natural predisposing risk factors.

However, a huge factor for hydro-geological risk is man: Too many people, uncontrolled urbanization, neglect of hillsides, irregular or illegal building, forest destruction, unsuitable cultivation techniques, are all key factors in the present, poor state of the Italian territory. The data in (Table 1) come from the Ministry of the Environment. Figure 9 shows the tematic map for the hydro-geological risk in Itlay.

The representation by means of a numerical table does not have anything like the same impact as the anamorphic map shown in Fig. 10. Indeed, in the anamorphic map of Italy, the regions of Valle d'Aosta, Liguria, Abruzzo, Molise and Basilicata, which account for almost all of the territory at high risk, appear greatly deformed and thus distort the numerical scale and intensify the concerned reaction amongst the population.

\section{Visual Representation of National Landslide Risk}

Landslide is " a movement of rock, earth or debris mass along a hillside". Many factors affect these destabilization processes, often complex and interconnected. Landslides vary in degree of danger, according to the mass and velocity of the matter in movement: A slow, comparatively small landslide is obviously not as dangerous as a huge, highspeed one (Fig. 12).

Table 1 . The data of hydro-geological risk in Italy

\begin{tabular}{lr}
\hline REGIONS & Municipalities with high risk (\%) \\
\hline Piemonte & 9,8 \\
Valle d'Aosta & 44,6 \\
Lombardia & 18,0 \\
Trentino Alto Adige & 6,5 \\
Veneto & 2,6 \\
Friuli Venezia Giulia & 2,7 \\
Liguria & 30,6 \\
Emilia Romagna & 11,7 \\
Toscana & 7,3 \\
Umbria & 27,2 \\
Marche & 19,5 \\
Lazio & 4,8 \\
Abruzzo & 24,6 \\
Molise & 51,5 \\
Campania & 26,1 \\
Puglia & 14,7 \\
Basilicata & 29,0 \\
Calabria & 16,6 \\
Sicilia & 5,9 \\
Sardegna & 5 \\
\hline
\end{tabular}

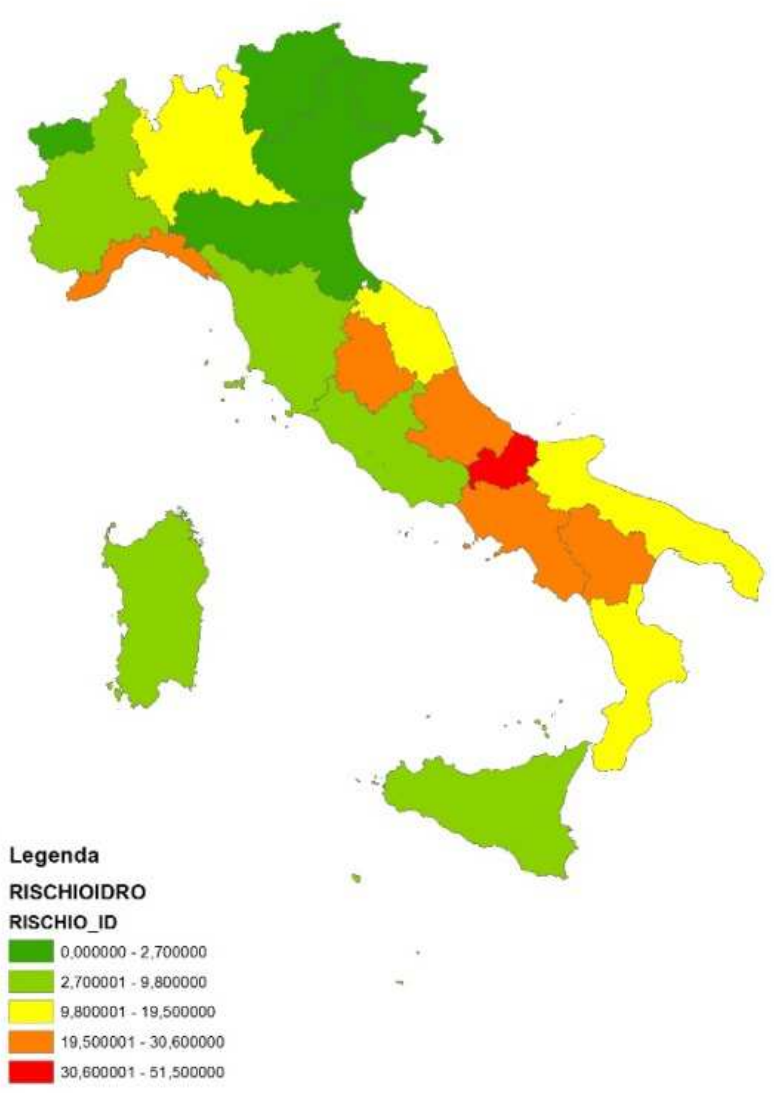

Fig. 9. Thematic cartogram of hydro-geological risk in Italy 


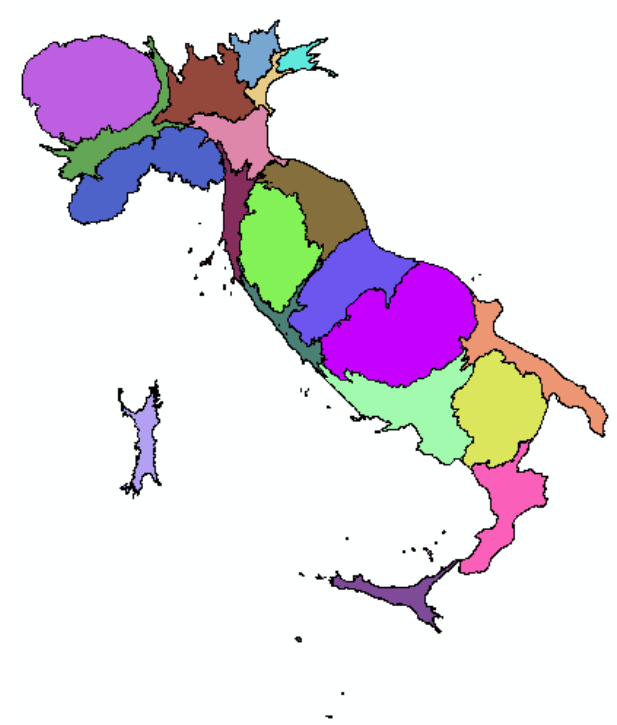

Fig. 10. Cartogram of hydro-geological risk in Italy

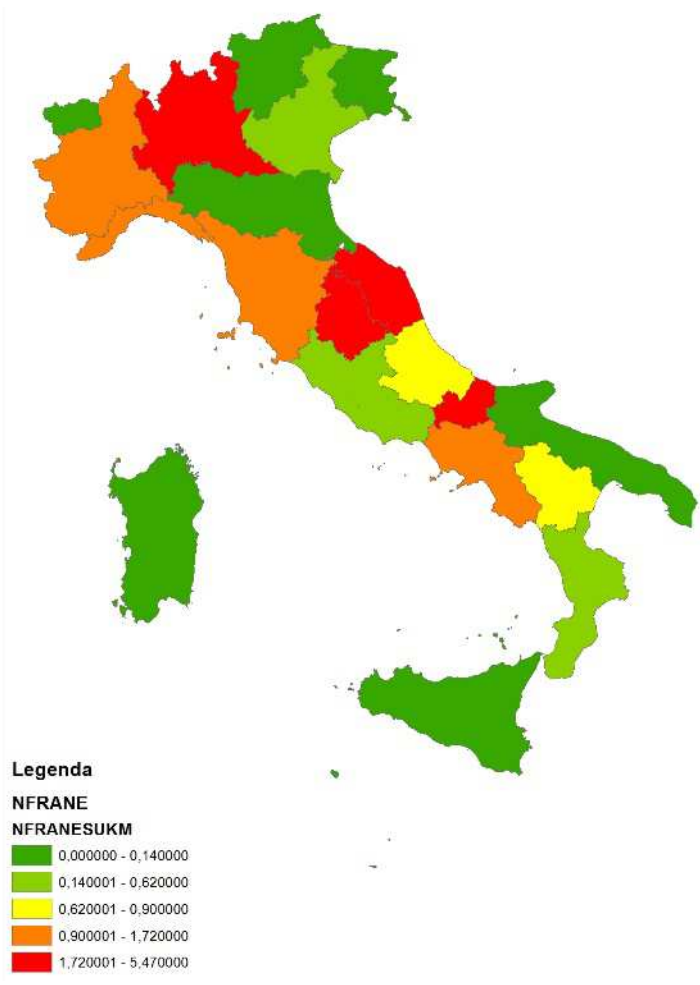

Fig. 11. Thematic map of landslide risk in Italy

\section{Visual Representation of National Seismic Risk}

Seismicity is the known frequency and intensity of local earthquakes and the known probability of a certain event of a given magnitude happening in a certain interval of time. Seismic risk shall be higher for a given magnitude of earthquake occurring more often in a time unit.

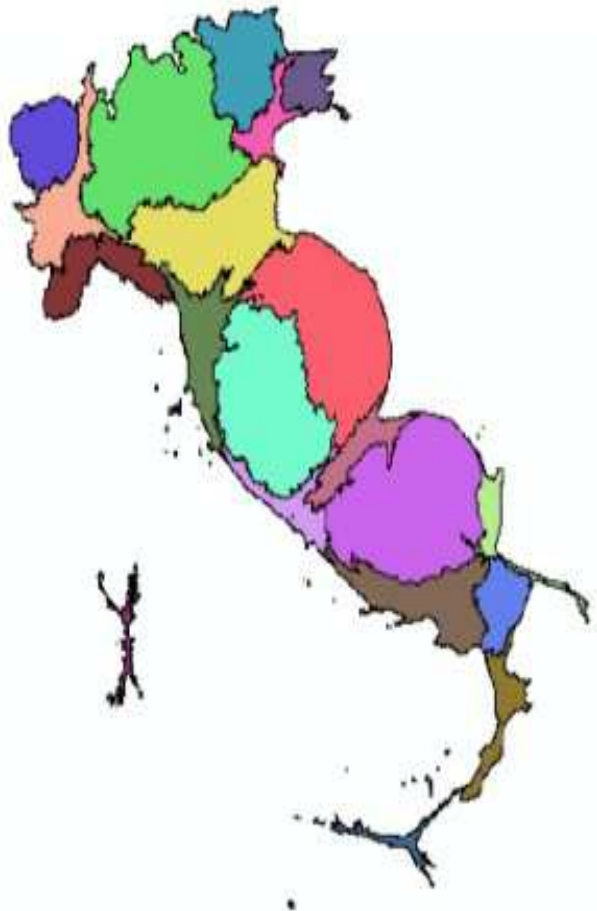

Fig. 12. Cartogram of landslide risk in Italy

Table 2. The data about Landslides

\begin{tabular}{llll}
\hline REGIONS & $\begin{array}{l}\text { Surface }[\mathrm{S}] \\
{\left[\mathrm{KM}^{2}\right]}\end{array}$ & $\begin{array}{l}\text { Landslides } \\
\text { Number }[\mathrm{N}]\end{array}$ & $\mathrm{N} / \mathrm{S}$ \\
\hline Piemonte & 25400 & 35.023 & 1,38 \\
Valle d'Aosta & 3260 & 4.359 & 1,34 \\
Lombardia & 23862 & 130.538 & 5,47 \\
Trentino Alto A. & 13600 & 11.380 & 0,84 \\
Veneto & 18391 & 9.476 & 0,52 \\
Friuli Venezia G. & 7855 & 5.253 & 0,67 \\
Liguria & 5420 & 7.515 & 1,39 \\
Emilia Romagna & 22450 & 70.037 & 3,12 \\
Toscana & 22997 & 29.208 & 1,27 \\
Umbria & 8455 & 34.545 & 4,09 \\
Marche & 9695 & 42.522 & 4,39 \\
Lazio & 17205 & 10.548 & 0,61 \\
Abruzzo & 10799 & 8.493 & 0,79 \\
Molise & 4438 & 22.527 & 5,08 \\
Campania & 13595 & 23.430 & 1,72 \\
Puglia & 19360 & 843 & 0,04 \\
Basilicata & 9992 & 9.004 & 0,90 \\
Calabria & 15081 & 9.417 & 0,62 \\
Sicilia & 25710 & 3.657 & 0,14 \\
Sardegna & 24090 & 1.523 & 0,06 \\
\hline
\end{tabular}

The basic principle of the chart is density, that is number of landslides per total surface area (Table 2 the data derive from the IFFI (landslip inventory) Project conducted by ISPRA (Higher Institute for Environmental research and Protection). The maps of Fig. 11 and 12 show him cartogram and the thematic representation of the landslides risk in Italy. 
Figure 13 and 14 are the cartogram and the thematic map of the seismic risk in Italy.

Expected damage quantifies seismic risk: Italy has a medium-high seismic risk (in terms of frequency and intensity), but a high vulnerability (owing to the general fragility of the territory and the built heritage) and a very high danger (due to the unique historical, monumental, artistic heritage and to population density. The data of seismic risk in Italy in percentage is stored in Table 3.

Table 3 . The data of seismic risk in Italy

\begin{tabular}{lr}
\hline REGIONS & $\begin{array}{c}\text { Municipalities with } \\
\text { medium or high seismic risk }(\%)\end{array}$ \\
\hline Piemonte & 3 \\
Valle d'Aosta & 0 \\
Lombardia & 3 \\
Trentino Alto A. & 0 \\
Veneto & 15 \\
Friuli Venezia G. & 67 \\
Liguria & 14 \\
Emilia Romagna & 31 \\
Toscana & 65 \\
Umbria & 75 \\
Marche & 95 \\
Lazio & 77 \\
Abruzzo & 82 \\
Molise & 89 \\
Campania & 89 \\
Puglia & 26 \\
Basilicata & 96 \\
Calabria & 100 \\
Sicilia & 91 \\
Sardegna & 0 \\
\hline
\end{tabular}

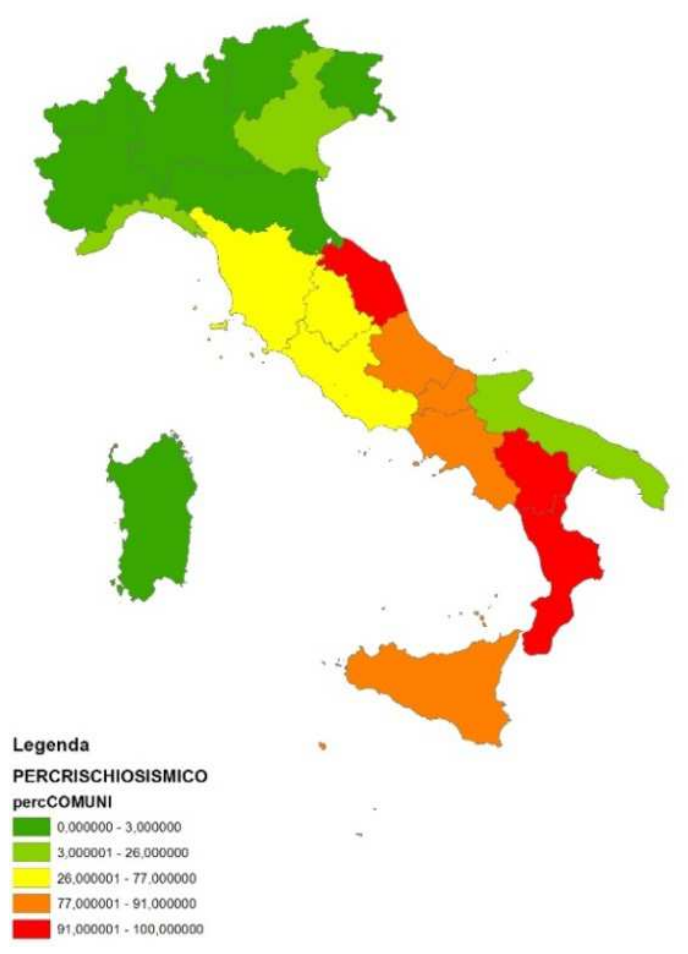

Fig. 13. Thematic map of seismic risk in Italy
As such, the country has a high risk in terms of expected damage, victims and costs.

\section{Visual Representation of Fire Risk}

A forest fire can generally spread through wooded, bush or cultivated areas, as well as through civil constructions and infrastructure in the surroundings, causing severe damage to vegetation and to human dwellings.

Table 4. The data of fire risk in Italy

\begin{tabular}{lr}
\hline REGIONS & Number of fires in 2010 \\
\hline Piemonte & 66.000 \\
Valle d'Aosta & 7.000 \\
Lombardia & 82.000 \\
Trentino Alto Adige & 39.000 \\
Veneto & 25.000 \\
Friuli Venezia Giulia & 53.000 \\
Liguria & 113.000 \\
Emilia Romagna & 19.000 \\
Toscana & 165.000 \\
Umbria & 40.000 \\
Marche & 9.000 \\
Lazio & 354.000 \\
Abruzzo & 64.000 \\
Molise & 74.000 \\
Campania & 543.000 \\
Puglia & 473.000 \\
Basilicata & 150.000 \\
Calabria & 652.000 \\
Sicilia & 1.159 \\
Sardegna & 797.000 \\
\hline
\end{tabular}

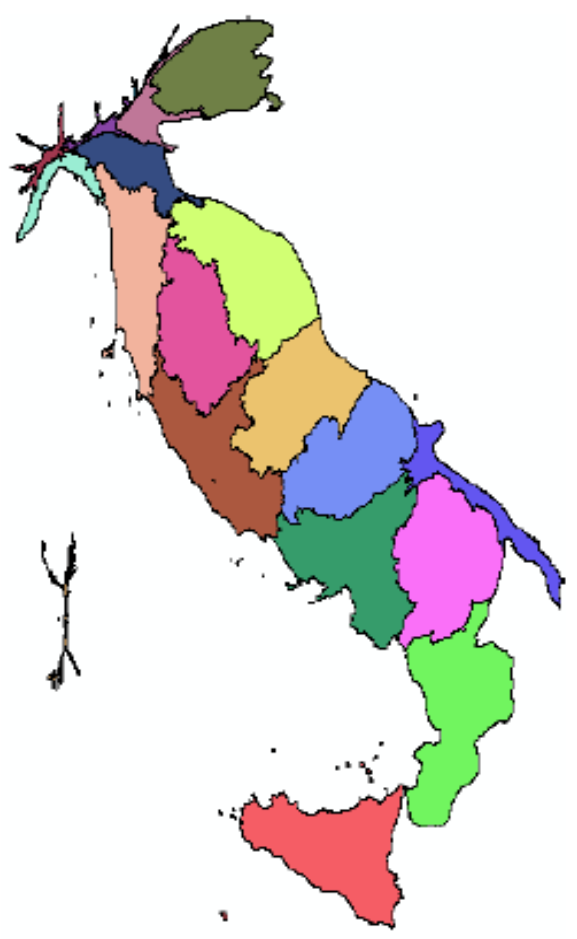

Fig. 14. Cartogram of seismic risk in Italy 
All Italy's regions may be prone to fire, albeit with differing levels of danger and at different times of the year. Climate and environmental conditions in Italy may cause fires in two seasons. In the North-the Alpine areaand in the higher Apennines, forest fires may develop in winter and spring (the dry season, with vegetation desiccated by frost); in summer, frequent rainfall reduces danger of fire (Table 4). Figure 15 and 16 are cartogram and thematic map of the fire risk in Italy.

In the peninsular areas, in contrast, with their Mediterranean climate, fires mainly develop in the summertime. However, some areas of Italy may experience fires at any time of year.

In the case below, the year 2010 has been examined.

The authors believe that the anamorphic maps are suitable to convey the information of the risk entity, while in a traditional thematic map this information is not easy to read without a proper legend.

Therefore, the authors think that the emotional impact of anamorphic charts is more relevant than that due to the classic thematic maps.

The authors would like to verify their idea carrying out statistical tests on a representative sample of students.

\section{Conclusion}

The histograms shown in the figures represent respectively the hydro-geological risk (Fig. 17), landslide risk (Fig. 18), seismic risk (Fig. 19) and fire risks (Fig. $20)$ in Italy.

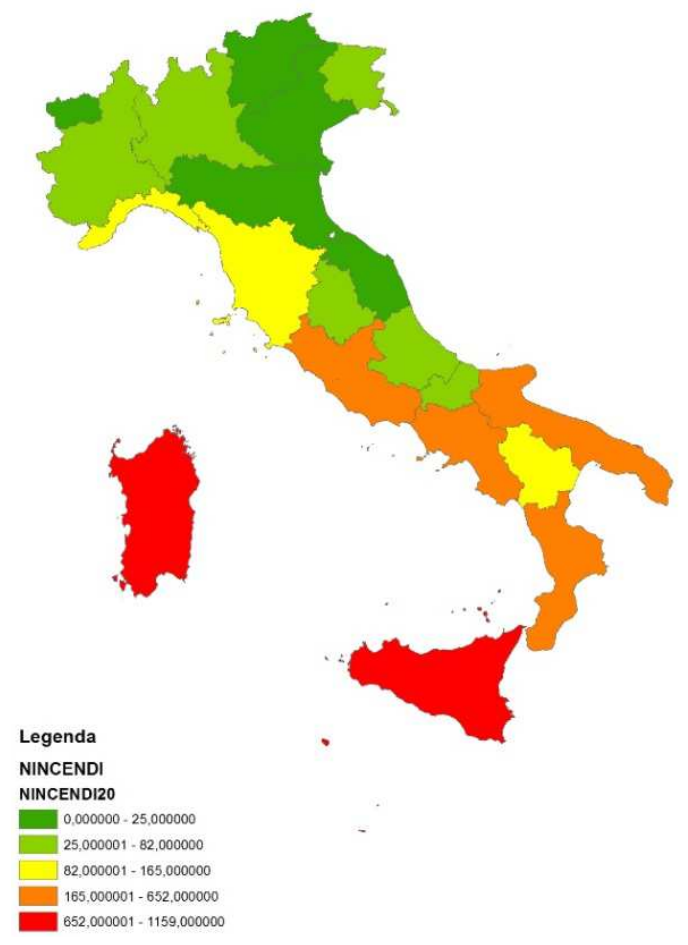

Fig. 15. Temathic map of fire risk in Italy

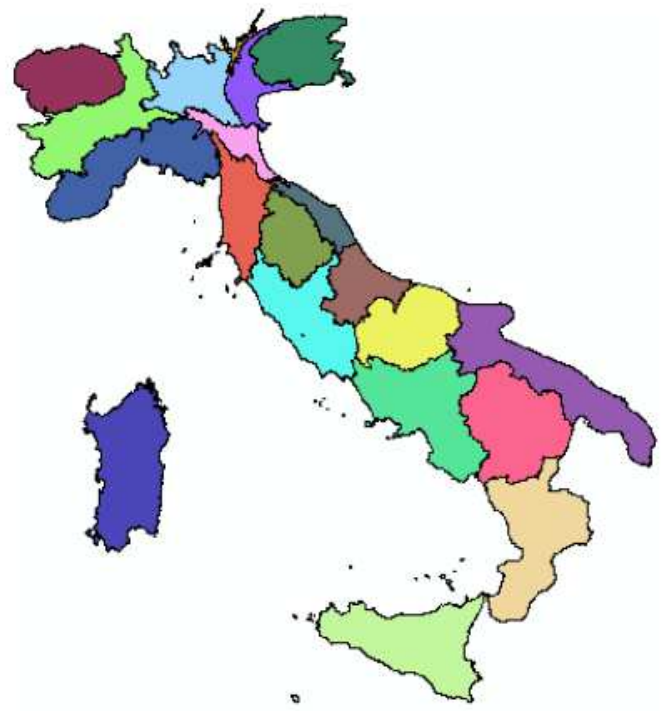

Fig. 16. Anamorphic cartogram of fire risk in Italy

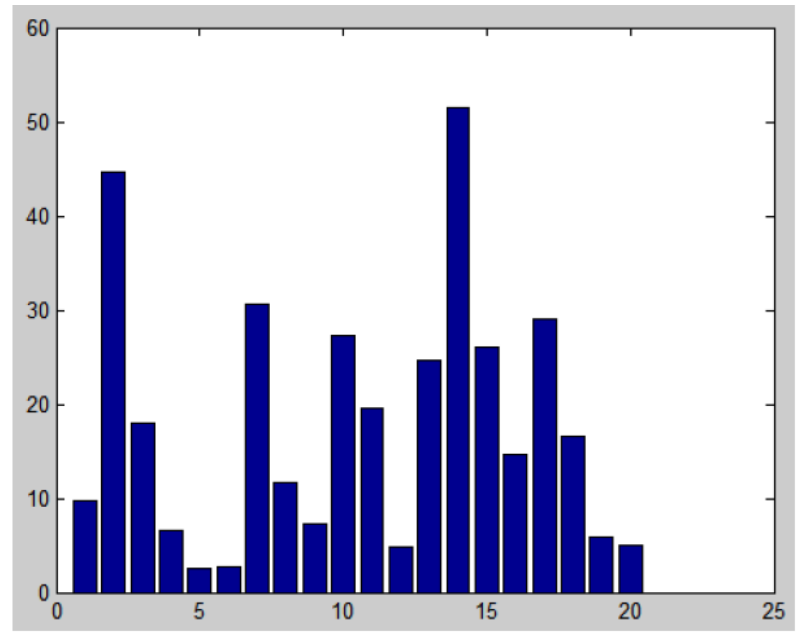

Fig. 17. Histogram showing hydro-geological risk

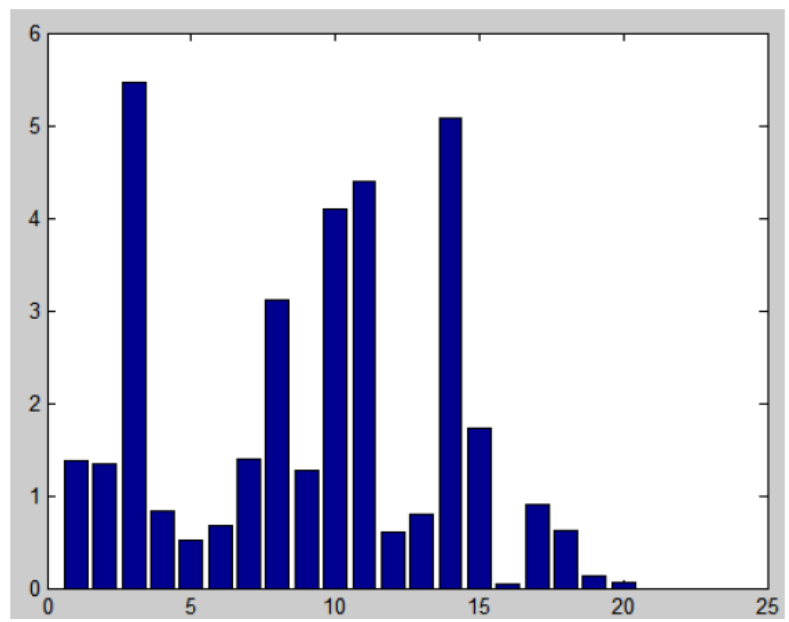

Fig. 18. Histogram showing landslide risk 
Notice that these classical performances of univariate statistics by their own nature do not give an immediate idea of spatiality of the phenomena.

The phenomena described above can be displayed using multivariate statistical representations, such as the previously-mentioned stars, Chernoff faces or other, better-known, forms (Zani, 2000).

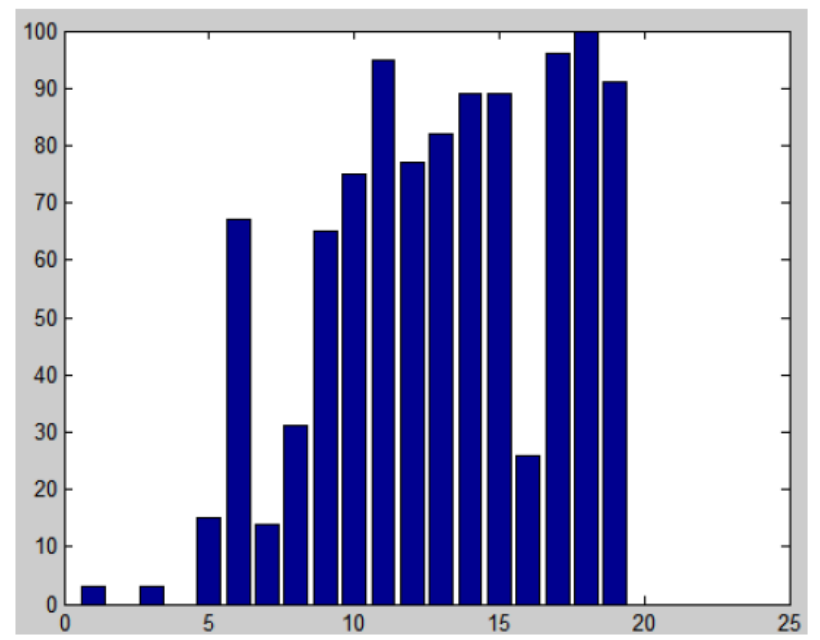

Fig. 19. Histogram showing seismic risk

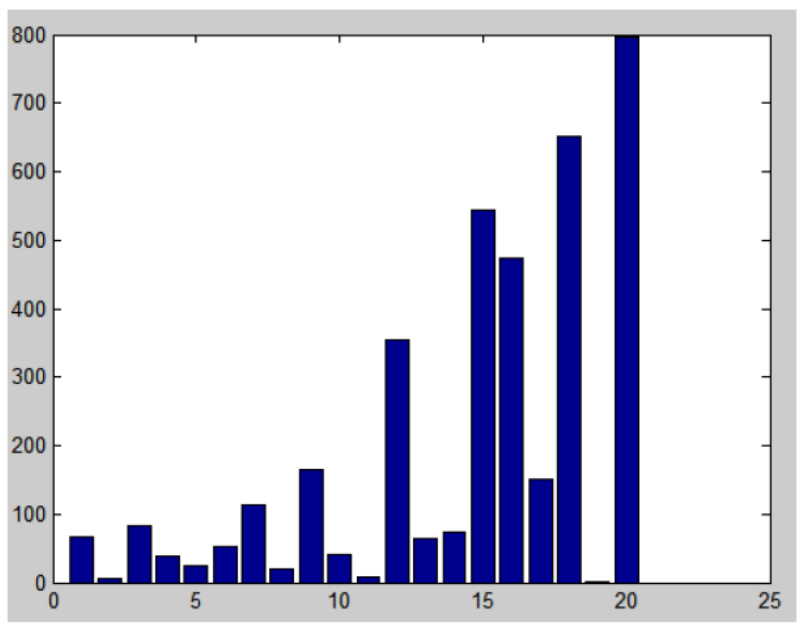

Fig. 20. Histogram showing fire risk

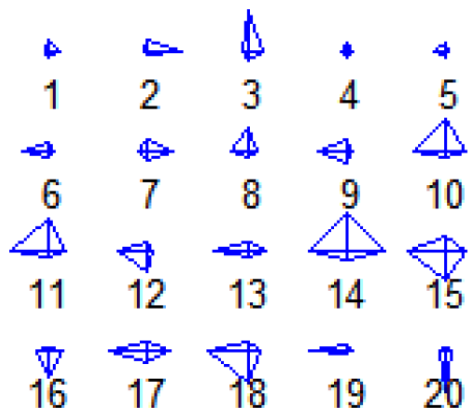

Fig. 21. Stars
The stars (Fig. 21) are equal in number to the multivariate sample size (in this case there are 20 regions), they are constructed from segments equal in number to that of the casual variables (the 4 environmental risks) and of a length proportional to the argument values.

Similarly, with little faces (Fig. 22), their number is equal to the sample size, while the differences in casual variable values are represented by the differing characteristics of the icon. It is to be noted that the characteristics of Chernoff faces are to do with face size, height of forehead, shape of forehead and jaw and so on.

Neither the stars nor the faces would appear to be obvious in their interpretation.

The more classical diagrams (scatterplot matrix and boxplot) are more frequently used, but do, however, require knowledge of statistics (Fig. 23).

Anamorphic maps may prove to be useful tools since alongside the spatial information of thematic maps they provide a more effective visual message.

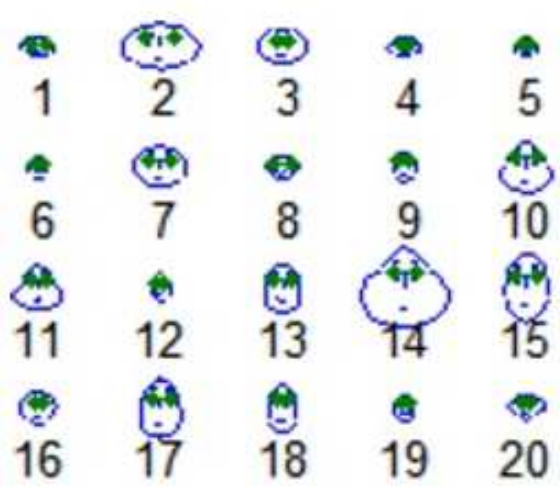

Fig. 22. Faces

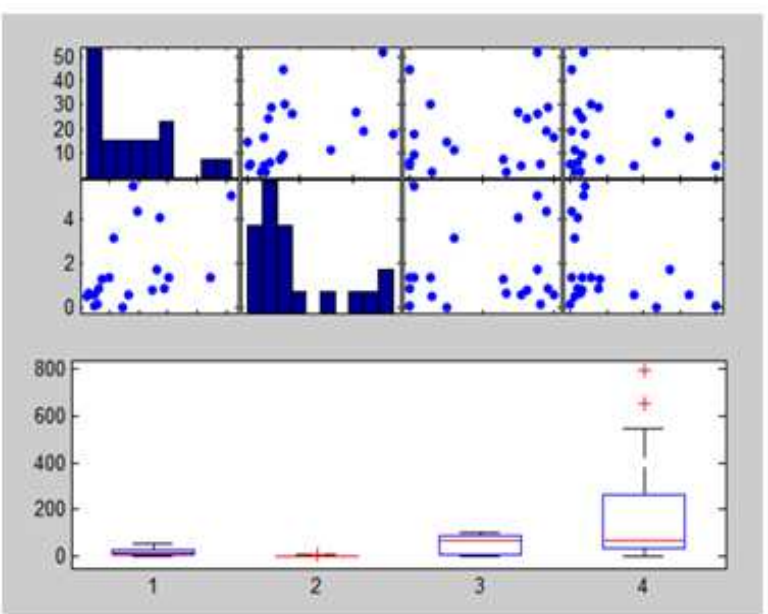

Fig. 23. Scatterplot matrix and boxplot 
The anamorphic cartogram is a link between Cartography, Geography and Statistics. It is the result of a cultural climate that, starting from the Arno Peters map (Peters, 1990), considers cartography (and GIS) not neutral, but a social product.

The anamorphic map applications are issues of collective interest (i.e., health, ...); the authors believe that these maps can also help to refine the environmental awareness.

\section{Acknowledgement}

The authors thank Eng. Paola Nanni, who collected the data.

\section{Funding Information}

The Hydro-Geological Risk data were provided by the Italian Ministry of Environment; the Landslide Risk data were provided by the Italian Institute for Civil Protection and Environmental Research (ISPRA); the Seismic Risk data were provided by the Italian Civil Protection; the Fire Risk data were provided by the Italian State Forestry Corps.

\section{Author's Contributions}

The contribution of the Authors is comparable.

\section{Ethics}

Using Anamorphic map for environmental purposes, thanks to its emphatic but rigorous representation of the data, could be an useful and concisely way to sensitize people to the real level of risk for the earthquake area and so on.

\section{References}

Baltrušaitis, J., 1978. Anamorfosi. Adelphi, Milano.

Ferretti, F., 2007. Il mondo senza mappe. Elisée Réclus e i geografi anarchici. Zeroincondotta, Milano.

Gastner, M.T. and M.E.J. Newman, 2004. Diffusionbased method for producing density-equalizing maps. Proceedings of the National Academy of Sciences of the United States of America.

Gombrich, E.H., 1965. Art and Illusion: A Study in the Psycology of the Pictorial Representation, Torino Einaudi.

Kemp, M., 1999. Immagine e verità. Il Saggiatore, Milano.

Odifreddi, P., 2011. Una via di fuga. Il grande racconto della Geometria moderna. Mondadori, Milano.

Panofky, E., 1984. La prospettiva come forma simbolica. Feltrinelli, Milano.

Peters, A., 1990. Atlante del mondo, Rizzoli, Milano.

Reclus, E., 1876-1894. Nouvelle géographie universelle: la Terre et les hommes (18 Volumes). Hachette, Paris.

Tobler, W., 1961. Map transformation of geographic space. PhD thesis. Department of Geography, University of Washington.

Tobler, W., 2004. Thirty-five years of computer cartograms. Assoc. Am. Geographers n. March

Tufte, E., 1983. The Visual Display of Quantitative Information. Graphics Press. Cheshire, CT.

Tukey, J., 1977. Exploratory Data Analysis. AddisonWesling, Reading MA.

Zani, S., 2000. Analisi dei dati statistici. Osservazioni multidimensionali. Giuffrè Editore, Milano. 